\title{
HACIA UNA CARTOGRAFÍA DEL DISPOSITIVO DEMOCRÁTICO GLOBAL
}

\author{
TOWARDS A CARTOGRAPHY OF THE GLOBAL \\ DEMOCRATIC MECHANISM
}

\section{VERS UNE CARTOGRAPHIE DU DISPOSITIF DÉMOCRATIQUE MONDIAL}

\author{
Mariela Cuadro \\ Consejo Nacional de Investigaciones en Ciencia y Tecnología \\ marielacuadro@yahoo.com.ar
}

Resumen: El texto parte de la sospecha de la existencia de un dispositivo democrático que funciona globalmente. Basándose en Michel Foucault, concibe al dispositivo como una red que conecta elementos heterogéneos y cuyo efecto es la producción de subjetividades. Así, haciendo un uso metodológico del mismo, vincula proposiciones éticas sobre la libertad, construcciones teóricas de las relaciones internacionales, prácticas políticas de Estados y organismos internacionales y construcciones normativas (específicamente, la responsabilidad de proteger) que acompañan las intervenciones internacionales en el Sur global, para reflexionar sobre la producción de un sujeto democrático, predicado de un gobierno liberal global.

Palabras clave: democracia liberal, subjetividad, gubernamentalidad global, dispositivo, gobierno liberal global

ABstract: The starting point for this paper is the suspected existence of a globally functioning operational democratic mechanism. Based on the work of Michel Foucault, it conceives this mechanism as a network that links up heterogeneous elements and has the effect of producing subjectivities. By making methodological use of this mechanism, it links ethical propositions about freedom, theoretical constructions of international relations, political practices of states and international organizations, and normative constructions (specifically, the responsibility to protect) that accompany international interventions in the Global South, in order to reflect on the production of a democratic subject, the predicate of a global liberal government. 
Keywords: liberal democracy, subjectivity, global governability, mechanism, global liberal government

\section{Traducción de Gonzalo Celorio Morayta}

RÉsumÉ: L'article part du soupçon qu'il pourrait exister un dispositif démocratique capable de fonctionner autour du monde. Michel Foucault imagine ce dispositif comme un réseau qui met en rapport des éléments hétérogènes, et dont l'effet est de construire des subjectivités. Son application méthodologique relie, entre elles, des propositions éthiques sur la liberté, des constructions théoriques des relations internationales, des pratiques politiques des États et des organisations internationales, ainsi que des constructions normatives -en particulier la responsabilité de protéger-associées aux interventions internationales dans le Sud mondialisé. Ceci mène à réfléchir sur l'avènement d'un sujet démocratique, tel qu'il est préconisé par un gouvernement libéral mondial.

Mots clefs: démocratie libérale, subjectivité, gouvernance mondiale, dispositif, gouvernement libéral mondial

Traducción de BERNARDo MABIRE

Fecha de recepción: abril de 2017

Fecha de aceptación: enero de 2019 
Estos conceptos no sirven para resumir la "coyuntura" histórica presente; más bien son herramientas para comprender algunas de las contingencias del sistema de poder que habitamos -o que nos habita- hoy. ${ }^{1}$

$\mathrm{D}$ ESDE el fin de la Guerra Fría, la democracia liberal se ha impuesto ética, teórica, política y normativamente a escala global, ocupando una posición privilegiada en la política internacional. Al ser homologada con la libertad, se ha expulsado a la democracia del ámbito político para colocarla en el campo de la ética. Este desplazamiento ha sido fomentado y ha tenido impacto en la disciplina de las relaciones internacionales (RI) que, a su vez, ha vinculado democracia con paz y derechos humanos. Estos desarrollos han sido acompañados por la práctica política: Estados y organismos internacionales han hecho eco de ellos y han colocado la democratización en un lugar privilegiado de sus respectivas agendas. Finalmente, a través de la responsabilidad de proteger se han buscado modos de convertirla en norma del derecho internacional. Estos elementos han actuado en conjunto y se han reforzado mutuamente, edificando un consenso en torno a la deseabilidad global de la democracia.

El presente texto parte de la sospecha de la existencia de una estrategia democrática a nivel global que se inserta en lo que será definido como gobierno liberal global. Esta noción se construirá desde la perspectiva de la gubernamentalidad, para la cual el liberalismo no es una doctrina económica ni ideológica, sino una forma de racionalidad de gobierno. Este texto sostiene que es posible vincular el liberalismo con un tipo particular de democracia (la liberal), pues para efectuarse precisa de un sujeto construido como individuo autogobernable. De este modo, se plantea que la expansión del

${ }^{1}$ Barry, A., T. Osborne y N. Rose, Foucault, and Political Reason. Liberalism, Neo-liberalism, and Rationalities of Government, Chicago, The University of Chicago Press, 1996, p. 4. 
liberalismo como racionalidad de gobierno no se realiza sólo a través de la imposición de una institucionalidad democrática, ni únicamente mediante la apertura de mercados para los capitales occidentales, sino también a través de la constitución de sujetos deseosos de autogobernarse.

El objetivo general del presente texto es rastrear la presencia en funcionamiento de lo que construirá como dispositivo democrático global, enmarcándolo en el liberalismo, entendido como forma de gubernamentalidad. Se trata de un esbozo que permita pensar la democracia liberal en el plano global de otra manera: hacer a un lado la democracia como objeto y, en cambio, enfocarse en las prácticas que la producen y los efectos que conlleva. En este sentido, es importante subrayar que de ningún modo se busca sellar una época bajo el signo democrático o caracterizar al liberalismo como ontológicamente democrático. Entre los efectos del dispositivo, se destaca la constitución de subjetividades. Así, se le dará a esta noción un uso metodológico que permitirá reflexionar en torno a cómo se produce el sujeto democrático en el plano global, aportando a los estudios sobre la dimensión de la subjetividad en las RI.

El artículo se divide en cuatro apartados y una conclusión. El primero elucida la noción de dispositivo. El segundo aborda la de gobierno liberal global como marco en el interior, a partir del cual funciona el dispositivo democrático global. El tercer apartado trabaja sobre la dimensión de la subjetividad en su relación con las RI. El último desarrolla los elementos que participan en la construcción de la noción de dispositivo democrático global, trazando relaciones que los vinculan. Finalmente, se ofrecen algunas observaciones a modo de cierre.

\section{Dispositivo}

Este texto se interesa en la utilidad metodológica de la noción de dispositivo, puesto que su articulación permite pen- 
sar en la convergencia de prácticas discursivas y no-discursivas en la constitución de subjetividades. En efecto, el dispositivo se considera de gran valor porque permite vincular elementos dispersos y heterogéneos en una estrategia que se considera impersonal. Al ser concebida como una composición de enunciaciones y visibilidades que "desindividualiza el poder", ${ }^{2}$ esta noción permite hacer una lectura no soberana del ejercicio del poder y, en cambio, entenderlo desde la perspectiva de la gubernamentalidad.

Dispositivo es una noción que se escabulle. Esto queda en evidencia en la pregunta ontológica que acompaña muchos de los textos que la han abordado. Con el objetivo de brindar una definición propia, este artículo se basará fundamentalmente en los desarrollos de Michel Foucault. Esto no significa que este texto se proponga como una exégesis del pensamiento del filósofo francés, ni que deba ser catalogado como un texto foucaultiano. En cambio, se propone utilizar las herramientas por él ofrecidas, reformarlas y deformarlas a fin de formular distintos abordajes de los discursos y las prácticas de la política internacional contemporánea.

Como sucede con la gran mayoría de sus conceptos, Foucault no usó el de dispositivo de una manera sistemática. Solamente en el marco de una entrevista que dio en 1977 postuló algo cercano a una definición del término, señalando sus principales características: 1) está formado por elementos heterogéneos (discursivos y no-discursivos) y el dispositivo constituye la red que es posible establecer entre éstos; 2) en el interior del dispositivo es posible identificar la naturaleza del lazo que puede haber entre esos elementos; 3) su emergencia responde a una urgencia, cumpliendo así con una función estratégica; 4) una vez constituido, el dispositivo se mantiene como tal a través de un doble proceso de sobrede-

${ }^{2}$ M. Foucault, Vigilar y castigar. El nacimiento de la prisión, Buenos Aires, Siglo Xxi, 1985, p. 205. 
terminación funcional y de relleno estratégico. ${ }^{3}$ Estos dos últimos procesos dan cuenta del carácter dinámico del dispositivo, debiendo reacomodarse constantemente a los efectos no intencionales que produce.

Esta suerte de definición fue entregada con posterioridad a la utilización de la noción en dos de sus libros: Vigilar y castigar e Historia de la sexualidad. En el primero, construyó la noción de dispositivo disciplinario y, en el segundo, la de dispositivo de la sexualidad. El resto de las menciones y utilizaciones de esta definición se deriva de seminarios, conferencias y entrevistas que el pensador francés brindó antes y después de la mencionada entrevista. Es el caso de los dispositivos de seguridad desarrollados en el seminario titulado "Seguridad, territorio, población".

Es posible identificar una diferencia entre la definición brindada en 1977 y las distintas utilizaciones de la noción en diferentes momentos, por un lado, y la construcción del dispositivo disciplinario, el de sexualidad y los de seguridad, por otro. En el primer caso, la definición es bastante laxa y permite pensar en la coexistencia de distintos dispositivos inscritos en relaciones de poder. En el extremo de esta primera concepción podría ubicarse al filósofo Giorgio Agamben, para quien un dispositivo es "cualquier cosa que tenga de algún modo la capacidad de capturar, orientar, determinar, interceptar, modelar, controlar y asegurar los gestos, las conductas, las opiniones y los discursos de los seres vivientes". ${ }^{4}$

En el segundo caso, en cambio, el dispositivo aparece como articulador de determinados modos de ejercicio del poder, incluso como constitutivo de los mismos, asemejándose a una idea de estructura ordenadora. ${ }^{5}$ Este último caso

${ }^{3}$ M. Foucault, "Le jeu de Michel Foucault", Dits et écrits 3 (1976-1979), París, Gallimard, 1994, pp. 298-328.

${ }^{4}$ G. Agamben, “¿Qué es un dispositivo?”, Sociológica, vol. 26, núm. 73, 2011, pp. 3-4.

5 O. Thomas, "Foucaultian Dispositifs as Methodology: The Case of Anonymous Exclusions by Unique Identification in India”, International Political Sociology, núm. 8, 2014, pp. 164-181. 
puede ser ejemplificado con la concepción que del término entrega Gordon quien, al analizar el concepto de dispositivo de seguridad, sostiene que se trata de un principio de método político, un "componente dominante" 6 que define ontológicamente a una sociedad.

Así, Peeters y Charlier identifican dos enfoques referentes al dispositivo: uno totalizante, que se asemeja a esta noción con la idea de una estructura u orden homogéneo, y otro más rizomático, que da cuenta de un fluir generalizado y constante de las relaciones sociales. Para estos autores la noción de dispositivo podría ubicarse entre estos dos enfoques. De este modo, lo definen de una manera que sienta bien al texto que aquí se presenta: el dispositivo es un "producto del trabajo del analista o del practicante que busca establecer correspondencias, articulaciones. El dispositivo es un término que permite designar un campo compuesto de elementos heterogéneos y tratar esta heterogeneidad".7

Esto significa que no existen dispositivos fuera de un trabajo de articulación. En efecto, es precisamente la relación que se establece entre los elementos heterogéneos lo que constituye al dispositivo. Así, los distintos elementos pueden cumplir con su función estratégica en la medida en que entran en relación, forman dispositivo y, por tanto, funcionan como "cajas de resonancia". ${ }^{8}$ Este texto intenta articular un dispositivo a partir de elementos heterogéneos con el objetivo de poder pensar a la democracia liberal de otro modo.

El dispositivo funciona articulando tres elementos fundamentales: poder, saber y subjetividad. De esta manera, establece una determinada distribución de lo visible y lo no-visible

${ }^{6}$ C. Gordon, "Governmental Rationality: An Introduction”, G. Burchell, C. Gordon y P. Miller, The Foucault Effect. Studies in Governmentality, Chicago, University Press, 1991, p. 20.

${ }^{7}$ H. Peeters, H. y P. Charlier, "Contributions a un théorie du dispositif”, Hermès, La Revue, vol. 3, núm. 25, 1999, p. 15.

8 S. Castro Gómez, Historia de la gubernamentalidad. Razón de Estado, liberalismo y neoliberalismo en Michel Foucault, Bogotá, Siglo del Hombre Editores, 2010, p. 64. 
y de lo enunciable y lo no-enunciable, configurando un campo de fuerzas que tiene como efecto la producción de subjetividades. Así, el dispositivo se caracteriza por ser productivo, transformando tanto al ambiente como a los sujetos cuyas vidas allí se desarrollan.

Efectivamente, el dispositivo es algo que hace ver y hace hablar, produce cosas visibles y enunciables. En palabras de Martínez Posada, "el dispositivo implica relaciones entre instituciones, prácticas sociales y modos de gobernar que buscan determinar las formas de ser, hacer y conocer del sujeto en un momento histórico determinado". ${ }^{9}$ En este sentido, el efecto del dispositivo no es tanto imponer determinadas conductas, sino marcar ciertas "tendencias o inclinaciones"10 en la subjetividad. De acuerdo con Peeters y Charlier, puede hacer esto porque también cumple una función normativa, indicando un deber ser mediante la construcción de ideales que influyen las prácticas de los sujetos. ${ }^{11}$ En el mismo sentido, Raffnsoe et al. afirman que se trata de una máquina eidética, postulando que es "una 'idea' vinculante y producida colectivamente", ${ }^{12}$ una "fuerza dominante"13 y no una influencia omnideterminante.

Ahora bien, siguiendo a Castro-Gómez, los dispositivos se inscriben en relaciones de poder y sólo cumplen su función inscritos en éstas. ${ }^{14}$ Esta concepción se aleja de aquella que postula que los dispositivos son constitutivos de modos de ejercicios de poder. ${ }^{15}$ En cambio, pueden entenderse como

${ }^{9}$ J. E. Martínez Posada, "El dispositivo: Una grilla de análisis en la visibilización de las subjetividades”, Tabula Rasa, núm. 19, 2013, p. 83.

${ }^{10} \mathrm{~S}$. Raffnsoe, M. Gudmand-Hoyer y M. Thaning, "What is a Dispositive? Foucault's Historical Mapping of the Networks of Social Reality", 2014, p. 4 [ms].

${ }^{11}$ Peeters y Charlier, "Contributions a un théorie du dispositif", art. cit.

${ }^{12} \mathrm{~S}$. Raffnsoe, M. Gudmand-Hoyer y M. Thaning, "What is a Dispositive? Foucault's Historical Mapping of the Networks of Social Reality" (s/p), 2014, p. 20, https://www.academia.edu/9838825

13 Ibid., p. 7.

14 Castro Gómez, op. cit.

15 Por ejemplo, O. Thomas, "Foucaultian Dispositifs as Methodology: 
condiciones de posibilidad y efectos de los mismos. En palabras de Castro-Gómez: "el dispositivo hace posible que unas determinadas relaciones de dominación y de gobierno puedan llegar a cristalizarse en un momento dado de la historia". ${ }^{16}$ De esta manera, el dispositivo hace efectivo un cierto modo de ejercicio de poder. Así, éste puede definirse como una red de relaciones entre objetos heterogéneos inscrita en una relación de poder que puede adoptar un carácter global. ${ }^{17}$

Este texto busca comenzar a trazar una posible cartografía del dispositivo democrático global. Si este ejercicio tiene sentido, es porque se considera que es uno de los dispositivos que, a través de la constitución del sujeto democrático a nivel global, efectúa y actualiza lo que se formulará a continuación como gobierno liberal global.

\section{GOBIERNO LIBERAL GLOBAL}

Sin ser foucaultiana, la noción de gobierno liberal global que se desarrollará a continuación a modo de marco dentro del cual se despliega el dispositivo democrático, se basa en la analítica de la gubernamentalidad de Foucault, puesto que fue en este contexto en el que el pensador francés trazó la idea de una racionalidad liberal de gobierno.

Foucault tampoco brindó una definición sistemática y acabada del concepto de gubernamentalidad. Por el contrario, le dio "muchos significados y usos". ${ }^{18}$ No obstante, es posible afirmar que existe una relación clara, aunque poco definida, entre gubernamentalidad y liberalismo. Por esta razón, hay

The Case of Anonymous Exclusions by Unique Identification in India”, International Political Sociology, núm. 8, 2014, pp. 164-181.

${ }^{16}$ Castro Gómez, op. cit., p. 67.

17 D. Cortez y G. Orozco, "Gubernamentalidad, biopolítica y dispositivos en relaciones internacionales”, Eidos, núm. 26, 2017, pp. 210-237.

18 M. Dean, "Governmentality”; B. Turner, K. Chang, C. Epstein, P. Kivisto, W. Outhwaite, M. Ryan (eds.), The Wiley Blackwell Encyclopedia of Social Theory, New Jersey, Wiley Blackwell, 2017, p. 2. 
quienes establecen una suerte de homogeneización entre ambos términos. Es el caso de Joseph, quien no sólo afirma que el elemento liberal de gobierno es una característica predominante de la gubernamentalidad, sino que asevera que "la gubernamentalidad tiene que ser entendida como esta forma de poder crecientemente liberal". ${ }^{19}$ En el otro extremo, hay casos en los que se soslaya la importancia del liberalismo en el desarrollo de la gubernamentalidad. Por ejemplo, Sending y Neumann desarrollan el concepto de gubernamentalidad global sin establecer ningún vínculo con éste. ${ }^{20}$

Este artículo se encuentra a caballo entre estos enfoques: sin considerarlos homologables, estima que ambos términos están íntimamente relacionados. Como prueba de ello basta con subrayar que, de acuerdo con Foucault, las tecnologías gubernamentales alcanzan su máximo despliegue en el siglo XviII con la emergencia del liberalismo. Esta íntima vinculación no sorprende si se tiene en cuenta que una de las características principales del poder, entendido en términos de gobierno, es que se sostiene sobre la libertad de acción de los gobernados, la cual, a su vez, está en el centro del liberalismo. ${ }^{21}$ Apoyado sobre estos supuestos, este texto concibe el liberalismo como una forma de racionalidad gubernamental. ${ }^{22}$

Según desarrolla Foucault en Nacimiento de la biopolítica, la racionalidad liberal de gobierno está basada en la máxima de que siempre se corre el riesgo de gobernar demasiado.

${ }^{19}$ J. Joseph, "Governmentality of What? Populations, States, and International Organisations", N. Kiersey y D. Stokes (eds.), Foucault and International Relations. New Critical Engagements, Nueva York, Routledge, 2011, p. 54.

${ }^{20}$ O. Sending y I. Neumann, "Governance to Governmentality: Analyzing NGOs, States and Power", International Studies Quarterly, núm. 50, 2006, pp. 651-672.

${ }^{21}$ M. Foucault, Nacimiento de la biopolítica, Buenos Aires, Fondo de Cultura Económica, 2007, p. 82.

${ }^{22}$ En coincidencia con C. Gordon, "Governmental Rationality: An Introduction"; G. Burchell, C. Gordon y P. Miller, The Foucault Effect. Studies in Governmentality, Chicago, University Press, 1991. 
Así, uno de los principios fundamentales del liberalismo es el de la autolimitación del gobierno. Éste se complementa por la tesis de la mano invisible del mercado, que plantea que los procesos económicos no pueden ser de su dominio porque se considera que el soberano no puede conocer la totalidad de los procesos económicos. Esta incapacidad de conocer un ámbito regido por intereses individuales naturales conduce al mandato del laissez-faire y a la incapacidad del soberano de intervenir en el mercado. ${ }^{23}$

Si el campo de gobierno no puede ser el ámbito económico, ¿cuál será el dominio de acción de esta nueva racionalidad? Foucault responde: la sociedad civil. Ésta emerge como "nuevo plano de referencia" ${ }^{4}$ que abarca a sujetos tanto económicos como jurídicos, al mercado y a la ley. ¿Y cómo funciona el gobierno en este nuevo dominio? ¿Cómo se gobierna a la sociedad civil? La gubernamentalidad implica concebir el poder como "un conjunto de acciones sobre acciones posibles; opera sobre el campo de posibilidad o se inscribe en el comportamiento de los sujetos actuantes: incita, induce, seduce, facilita o dificulta; amplía o limita, vuelve más o menos probable; de manera extrema, constriñe o prohíbe de modo absoluto; con todo, siempre es una manera de actuar sobre un sujeto actuante o sobre sujetos actuantes, en tanto que actúan o son susceptibles de actuar". ${ }^{25}$

Dos conclusiones pueden extraerse de esta afirmación. En primer lugar, que el objeto de gobierno no es únicamente concebido como un ente pasivo, sino que se lo considera también un sujeto activo. De este modo, el poder no se ejerce sobre la sociedad civil, sino a través de ella, apuntando a su autogobierno. En segundo lugar, que debe abrirse un campo de acciones posibles. En efecto, puesto que el poder

23 M. Foucault, Nacimiento de la biopolítica, Buenos Aires, Fondo de Cultura Económica, 2007.

24 Ibid, p. 335.

${ }^{25}$ M. Foucault, "El sujeto y el poder", H. Dreyfus y P. Rabinow, Michel Foucault: Más allá del estructuralismo y la hermenéutica, México, unam, 1988, p. 151 . 
así concebido sólo puede ejercerse si el sujeto es libre de actuar, para la concepción del poder como gobierno la libertad y su producción son fundamentales: "la nueva razón gubernamental tiene necesidad de libertad, el nuevo arte gubernamental consume libertad. Consume libertad: es decir que está obligado a producirla”. ${ }^{26}$

Esta última cuestión es crucial para la concepción de gobierno liberal sobre la que se sostiene el presente texto. El dispositivo democrático se desmarcará de la política doméstica, se globalizará y se pondrá en funcionamiento, particularmente en el marco de prácticas intervencionistas sobre Estados y poblaciones del Sur global (se hagan o no efectivas las intervenciones). Estas prácticas se comprenderán como productoras globales de libertad y no sólo como consumidoras de ésta.

En este sentido, el artículo se diferencia de buena parte de la literatura de la gubernamentalidad, dedicada al estudio de sociedades donde gobierna el "liberalismo avanzado", porque considera que el ejercicio gubernamental del poder sólo puede desplegarse en el marco de sociedades (ya) "libres". ${ }^{27}$ Este enfoque se concentra en el aspecto consumidor de libertad del gobierno liberal y, al hacerlo, tiende a describir las prácticas intervencionistas como "iliberales". ${ }^{28}$ De este modo, acaba construyendo una idea de liberalismo que lo contrapone a la violencia.

Este artículo busca concentrarse en el aspecto productor de libertad del gobierno liberal, aspecto que, de acuerdo con Foucault, implica "limitaciones, controles, coerciones, obligaciones apoyadas en amenazas, etcétera”. ${ }^{29}$ Así, pone el foco

${ }^{26}$ Foucault, Nacimiento de la biopolítica, op. cit. pp.83-84.

27 N. Rose, P. O’Malley y M. Valverde, “Governmentality”, Annual Review of Law and Social Sciences, núm. 2, 2006, pp. 83-104.

28 Por ejemplo, B. Hindess, "Liberalism -what's in a name?", W. Larner y W. Walters, (eds.), Global Governmentality: Governing International Spaces, Nueva York, Routledge, 2004, pp. 23-39; y M. Dean, Governmentality. Power and Rule in Modern Society, Londres, Sage, 2010.

${ }^{29}$ Foucault, Nacimiento de la biopolítica, op. cit. p. 84. 
en el carácter violento del gobierno liberal y sostiene que para hacerlo no precisa recurrir a nociones que refieren a otras formas de ejercicio de poder, ${ }^{30}$ sino concentrarse en el carácter singular de su modo de intervención. En efecto, “el poder moderno es distintivo por su punto de aplicación. Y el punto de aplicación del poder moderno no es tanto el cuerpo del sujeto soberano [...] como las condiciones en las cuales ese cuerpo vivirá y definirá su vida”. ${ }^{31}$

Así, el autogobierno basado en la libertad no debe confundirse con la ausencia de gobierno: el liberalismo gobierna a través de la intervención en las condiciones de la libertad. Esto significa que no lo hace a través de la intervención directa sobre la conducta del objeto de gobierno de un modo detallado, reglamentando movimientos corporales y mentes como en el caso de la disciplina que Foucault desarrollara en Vigilar y castigar, sino indirectamente, en el marco donde ésta se desarrolla. Así, sin anular la libertad de los sujetos, la produce y la conduce.

La ley es el medio a través del cual se hace efectiva esta intervención. Por ello, Foucault sentencia que el liberalismo se caracteriza por "ningún intervencionismo económico o el mínimo intervencionismo económico y el máximo intervencionismo jurídico". ${ }^{32}$ Ahora bien, el lugar que ocupa la ley en el liberalismo no está vinculado con un "juridicismo que le fuera natural, sino [con que] la ley define formas de intervenciones generales excluyentes de medidas particulares,

${ }^{30}$ En este sentido se sigue a aquellos autores que se permiten pensar la relación entre liberalismo y violencia. Por ejemplo, M. Dillon, M. y J. Reid, The liberal way of war. Killing to make life live, Nueva York, Routledge, 2009; V. Jabri, "La guerre et l'État libérale démocratique", Cultures et conflits, núm. 61, 2006, pp. 9-34; L. Odysseos, "Liberalism's war, liberalism's order: Rethinking the global liberal order as a 'global civil war' ", documento preparado para el taller Liberal Internationalism, workshop preISA, San Francisco, 25 de marzo de 2008.

31 D. Scott, "Colonial Governmentality”, Social Text, núm. 43, 1995, pp. 198-199.

${ }^{32}$ Foucault, Nacimiento de la biopolítica, op. cit., p. 199. 
individuales y excepcionales, y porque la participación de los gobernados en la elaboración de la ley, en un sistema parlamentario, constituye el modo más eficaz de economía gubernamental". ${ }^{33}$ Es decir que la ley permite el desarrollo de tres elementos fundamentales de la racionalidad liberal de gobierno: una intervención general sobre las condiciones de libertad, la autolimitación en el ejercicio del poder y el devenir de los objetos de gobierno también en sujetos.

Desde esta perspectiva, entonces, la participación de los gobernados en su propio gobierno (autogobierno) no se debe a una supuesta naturalidad de los derechos o las libertades de los individuos, sino a que la gubernamentalidad liberal "sujeta la racionalidad del gobierno, del ejercicio del poder político, a la libertad y a la racionalidad interesada de los propios gobernados". ${ }^{34}$ Es decir que, por sus características intrínsecas, el gobierno liberal depende del autogobierno de los gobernados. De este modo, la concepción del gobierno liberal de Foucault permite pensar el Estado de derecho y la democracia liberal como instrumentos de esta racionalidad de gobierno, aún cuando democracia y liberalismo sean dos conceptos que no han estado en consonancia desde siempre. ${ }^{35}$

Si bien puede leerse que en Foucault esta concepción del gobierno liberal se encuentra restringida a los límites del Estado-nación, el presente texto sostiene que puede globalizarse. La posibilidad de esta lectura alternativa se encuentra en el propio Foucault quien, al afirmar que el objeto de gobierno no es más el territorio, sino "una suerte de complejo compuesto de hombres y cosas", ${ }^{36}$ desvincula gobierno de

33 Ibid., p. 363.

${ }^{34}$ G. Burchell, "Peculiar interests: Civil society and 'governing the system of natural liberty' ”, G. Burchell, C. Gordon, P. Miller, P. (eds.), The Foucault Effect. Studies in Governmentality, Chicago, The University of Chicago Press, 1991, p. 139.

$35 \mathrm{Al}$ respecto, ver M. Dean, Governmentality. Power and Rule in Modern Society, Londres, Sage Publications, 2010.

36 M. Foucault, "Governmentality", Burchell, Gordon y Miller, The Foucault Effect, art. cit. p. 93. 
territorio. Incluso más: los dispositivos de seguridad -principal técnica de la gubernamentalidad-son los encargados de producir un espacio sin fronteras, donde la circulación se encuentre libre de obstáculos. ${ }^{37}$ De allí la posibilidad de la emergencia de la noción de gubernamentalidad global.

Esta última no ha carecido de detractores. Una de las críticas que más ha resonado fue la que sostiene que Foucault se dedicó a realizar análisis "micro" y, por lo tanto, poco puede servir para pensar el nivel "macro". ${ }^{38}$ Como sostiene Vrasti, la obsesión con los niveles de análisis es más propia de la disciplina de las RI que de Foucault. ${ }^{39}$ Efectivamente, el pensador francés se destacó por buscar romper las dicotomías naturalizadas que organizan el poder, el saber y la subjetividad, incluyendo la que coloca en campos separados a lo micro y lo macro. Su redefinición del poder mediante la noción de gubernamentalidad también facilita este movimiento.

Una respuesta semejante podría darse a una segunda crítica a la noción de gubernamentalidad global, íntimamente relacionada con la primera. De acuerdo con ésta, la globalización de la gubernamentalidad no es posible pues el poder a escala global se ejerce "de arriba hacia abajo". Más allá de que el supuesto es en sí mismo debatible, esta crítica se sostiene sobre la idea de que los estudios de gubernamentalidad admiten una única (y opuesta) direccionalidad: "de abajo hacia arriba". ${ }^{40}$ Desde aquí se sostiene que, en tanto y en cuanto la analítica de la gubernamentalidad no pone el foco en los actores, sino en prácticas y procesos de conducción de conductas, la gubernamentalidad admite múltiples direccionalidades.

${ }^{37}$ M. Foucault, Sécurité, territoire, population, París, Gallimard, 2004.

38 J. Selby, "Engaging Foucault: Discourse, Liberal Governance and the Limits of Foucauldian IR", International Relations, vol. 21, núm. 3, 2007, pp. 324-345.

${ }^{39}$ W. Vrasti, "Universal but not truly 'global': governmentality, economic liberalism, and the international”, Review of International Studies, vol. 39, núm. 1, 2013, pp. 49-69.

${ }^{40}$ N. Rose, P. O’Malley, M. Valverde, M.; "Governmentality”, art. cit. 
Por otra parte, la gubernamentalidad global se ha convertido en otro locus de debate de las RI entre las perspectivas más tendientes a descentralizar el estudio de la política global de la omnipresencia del Estado y aquéllas con una concepción estatocéntrica de las relaciones de poder internacionales. En efecto, su valor radica en que permite eludir el nacionalismo metodológico que pervade a la disciplina, apuntando al análisis de la convergencia de discursos, instituciones, problematizaciones, procesos y redes constitutivas de un espacio y de una política global. ${ }^{41}$

Algunos partidarios de la gubernamentalidad global sostienen que ésta funciona únicamente como dispositivo de análisis. ${ }^{42}$ Siguiendo a Kiersey, este artículo considera que también opera en un segundo registro: como modo específico e histórico del arte de gobierno. ${ }^{43}$ Así, Foucault pensó al liberalismo y al neoliberalismo como formas de gubernamentalidad, es decir, como racionalidades históricas de gobierno. Analizadas desde la analítica de la gubernamentalidad, estas dos formas aparecen como proyectos positivos de gobierno, lo que significa que el foco del análisis está puesto en lo que producen con miras a gobernar. ${ }^{44}$

Por lo tanto, si este texto se decide por hacer a un lado el término gubernamentalidad global y, en cambio, adopta el de gobierno liberal global, lo hace por dos razones. Por un lado, para dar cuenta de una forma específica que adopta la gubernamentalidad global en el actual momento histórico, en el cual se inserta el dispositivo democrático global, objeto

${ }^{41}$ W. Larner y W. Walters, "Introduction. Global Governmentality: Governing International Spaces", en Larner y Walters (eds.), op. cit. pp. 1-20.

42 Loc. cit.

43 N. Kiersey, "Neoliberal Political Economy and the Subjectivity of Crisis: Why Governmentality is not Hollow", N. Kiersey y D. Stokes (eds.), Foucault and International Relations. New Critical Engagements, art. cit.

${ }^{44}$ C. Rojas, "Governing through the social: Representations of poverty and global governmentality", en Larner y Walters (eds.), op. cit. pp. 97115. 
de este trabajo. Por otro lado, porque, como afirma Hindess, se considera que el nombre es de extrema importancia y que el uso del adjetivo liberal puede tener "implicaciones significativas para el análisis político e histórico". ${ }^{45}$

En síntesis, el término gobierno liberal global se utiliza aquí para dar cuenta de una racionalidad específica de gobierno que precisa de la libertad para ejercerse, es decir, que es consumidor y productor de libertad. En tanto y en cuanto la racionalidad gubernamental se basa en un poder ejercido a través de sujetos libres, el gobierno liberal global gobierna mediante una intervención ya no directa, detallada y reglamentada sobre la conducta de su objeto/sujeto de gobierno, sino a través de una intervención "ambiental”. Es decir, que el gobierno liberal global interviene sobre las condiciones en las que se desarrolla la vida de la población global. La ley aparece como el medio predilecto de esta intervención, puesto que permite una intervención general, un gobierno autolimitado y la participación de los gobernados en su propio gobierno (autogobierno). La hipótesis de este artículo es que estas cuestiones se logran mediante la instauración de la democracia en los diversos países objeto de intervención.

Si bien suele no ser exitosa, esta instauración viene acompañada por un importante despliegue de discursos que apuntan a la constitución de una subjetividad democrática no sólo en la población blanco de las intervenciones, sino también en los espectadores. De esta manera, el intervencionismo en el marco del gobierno liberal global pone en funcionamiento un dispositivo democrático que refuerza el deseo democrático de los sujetos expuestos a tales discursos.

Así, el dispositivo democrático global encuentra su condición de posibilidad en el marco de esta específica forma de gubernamentalidad global y, al mismo tiempo, tiene como efecto que ésta se constituya. Como se sostuvo en el apartado anterior, esto último no significa que sea el único articulador de este modo de ejercicio del poder o que funcione como

${ }^{45}$ Hindess, art. cit. p. 23. 
una estructura ordenadora del mismo. En cambio, su efecto radica en que constituye inclinaciones en las subjetividades, necesarias para el despliegue del gobierno liberal global.

\section{SUBJETIVIDAD Y RI}

Desde los estudios de gubernamentalidad global en las RI, frecuentemente se plantea que ésta se ejerce desde las instituciones internacionales sobre los Estados. ${ }^{46} \mathrm{La}$ noción de dispositivo democrático global aspira a pensar su efecto no sólo en los Estados donde se interviene, sino en la subjetividad de los objetos/sujetos de tales intervenciones y de quienes son sus espectadores.

Si la libertad de los sujetos es un elemento central de la concepción del poder como gobierno, puede entenderse entonces que la perspectiva de la gubernamentalidad no sólo permita incorporar la cuestión de la subjetividad al análisis de las relaciones de poder, sino que obligue a hacerlo. ${ }^{47}$ Efectivamente, desde esta perspectiva analítica, la subjetividad aparece como el "locus principal del gobierno", ${ }^{48}$ puesto que, como se desarrolló, la racionalidad del gobierno liberal está basada en la racionalidad de los propios gobernados.

Desde la perspectiva liberal, al sujeto se le concibe como individuo naturalmente libre y portador de derechos fundamentales. Este supuesto es el que permite concebir la demo-

${ }^{46}$ Joseph, art. cit.; L. Zanotti, "Governmentalizing the Post-Cold War International Regime: The un Debate on Democratization and Good Governance", Alternatives, núm. 30, 2005, pp. 461-487. Hindess, por su parte, agrega como objeto del ejercicio del poder liberal a nivel internacional a las poblaciones pero, al plantear que esto se realiza con la mediación del Estado, continúa poniendo el foco en este último, B. Hindess, "Neoliberal Citizenship”, Citizenship Studies, vol. 6, núm.2, 2002, pp. 127-143.

47 Castro Gómez, op. cit.

${ }^{48}$ W. Vrasti, "Universal but not truly 'global': governmentality, economic liberalism, and the international", Review of International Studies, vol. 39, núm. 1, 2013, p. 60. 
cracia como la única forma política legítima, pues sería la que más se acercaría a esta naturaleza del ser humano. Además, explica que el liberalismo en las RI soslaye la pregunta por el sujeto, puesto que lo considera como un dato dado y no como producto de relaciones sociales de poder. Además de pensar en su constitución, reflexionar en torno a la subjetividad en el plano global supone también correr la atención del interés como categoría nodal de las RI y, en cambio, enfocarla en una de las fuerzas más potentes e instrumentalizadas de la hora actual: la fuerza del deseo.

Desde otra disciplina, Guattari auguraba la posibilidad de pensar una subjetividad global a fines del siglo pasado cuando daba cuenta de una subjetividad desterritorializada, propia del capitalismo. ${ }^{49}$ En RI la dimensión de la subjetividad fue abordada por el constructivismo, por el decolonialismo y por el posestructuralismo, dimensión sobre la cual Louiza Odysseos es una de las académicas más agudas .

Esta autora reflexiona acerca de la producción global de lo que denomina homo juridicus, sujeto construido a través del discurso y la práctica de los derechos humanos. De acuerdo con Odysseos, el resultado de esta producción es un sujeto autogobernable que funciona como predicado de la gubernamentalidad neoliberal. ${ }^{50} \mathrm{El}$ presente artículo no se enfoca en la cuestión de los derechos humanos, sino en la democracia (aunque, como se verá, ambos temas aparecen vinculados), intentando responder al interrogante de cómo se construye el sujeto democrático. Al igual que en el caso del homo juridicus de Odysseos, se considera el sujeto democrático un sujeto que se concibe como individuo libre, racional y responsable de sí mismo y que, por tanto, está deseoso de autogobernarse. Así, la constitución de esta particu-

${ }^{49}$ F. Guattari y S. Rolnik, Micropolítica. Cartografía del deseo, Petrópolis, Traficantes de sueños, 2006, p. 39.

${ }^{50}$ L. Odysseos, "Human Rights, Liberal Ontogenesis and Freedom: Producing a Subject for Neoliberalism?”, Millenium Journal of International Studies, vol. 38, núm. 3, 2010, pp. 747-772. 
lar subjetividad contribuye al despliegue del gobierno liberal global tal como fue definido anteriormente.

Para reflexionar en torno de este sujeto, el presente artículo se vale del concepto de dispositivo democrático global, cuyo principal efecto se considera que es la constitución de sujetos deseantes de la democracia, es decir, sujetos que ejercen su libertad en el interior de campos preestructurados de expresión y acción. De este modo, se afirma que el dispositivo democrático global presta asistencia al desarrollo del gobierno liberal global, constituyendo sujetos con vocación de gobernarse a sí mismos.

\section{HACIA UNA CARTOGRAFÍA DEL DisPositivo DEMOCRÁTICO GLOBAL}

El significante "dispositivo democrático" aparece en múltiples textos académicos sin mayores explicaciones acerca del porqué de su utilización..$^{51}$ Quien ha profundizado en este concepto ha sido Luciana Cadahia. En su texto, cuyo objetivo es entablar una discusión en torno al lugar que en la democracia ocupan los principios de igualdad y de libertad, la filósofa equipara dispositivo con discurso, entendiendo a la democracia liberal como una "estrategia discursiva" ${ }^{52}$ En este sentido es que la concibe como dispositivo, es decir, como "un conjunto de prácticas y mecanismos que tienen por finalidad provocar un determinado efecto sobre la conducta de quienes se encuentran sujetados a ese discurso". ${ }^{53}$ Este texto se diferencia de aquel en dos aspectos. Por un lado, como se sostuvo, se

${ }^{51}$ Por ejemplo, S. Ortiz Leroux, "La interrogación de lo político: Claude Lefort y el dispositivo simbólico de la democracia”, Andamios, 2006, pp. 79-117.

${ }^{52}$ L. Cadahia, "Entre la liturgia y el desencanto: la profanación del dispositivo democrático", A. Bermejo Salar, Umbrales filosóficos. Posicionamientos y perspectivas del pensamiento contemporáneo, Murcia, Ediciones de la Universidad de Murcia, 2010, p. 68.

${ }^{53}$ Loc. cit. 
basa en la idea de que los elementos puestos en relación por los dispositivos son tanto discursivos como no-discursivos. Por otro lado, se concentra en la democracia como dispositivo global.

Como se planteó, la noción de dispositivo democrático global cuya cartografía comienza a esbozarse aquí permite evitar tanto las preguntas ontológicas acerca de la democracia como aquéllas funcionalistas y, en cambio, centrarse en su dimensión subjetiva, comenzando a indagar en cómo los seres humanos de todo el globo devenimos sujetos deseosos de vivir en democracia. El interés en realizar este ejercicio estriba en que se sospecha que la democracia ayuda a concretar la necesidad que tiene la racionalidad liberal gubernamental de sujetos concebidos como individuos libres. En este sentido, se considera que indagar en la dimensión de la subjetividad en el marco del despliegue de la democracia a nivel global es fundamental para comprender el gobierno liberal global. Dado el lugar central que ocupa la subjetividad en la perspectiva de la gubernamentalidad, esta última resulta de mucha ayuda para pensar en el rol que desempeña la democracia en el universo liberal.

Si el dispositivo es una red de relaciones entre elementos heterogéneos, ¿qué elementos del campo de la política mundial pueden identificarse como partes del dispositivo democrático global? ¿Qué prescripciones éticas, conceptos científicos, prácticas políticas y normas jurídicas funcionan desde sus respectivas especificidades y confluyen en la constitución de un sujeto democrático a nivel global? El texto identifica cuatro elementos que pueden articularse bajo la forma de un dispositivo democrático global puesto en funcionamiento durante las últimas intervenciones en el Sur global. Sin pretender exhaustividad, el artículo busca que sirvan como puntapié inicial para la identificación de muchos otros. Estos cuatro elementos son: el uso de la significante libertad en el marco de los procesos intervencionistas; el modo de la incorporación de la democracia en la disciplina de las RI; prácticas políticas de intervención y democrati- 
zación llevadas adelante por las distintas administraciones estadounidenses y por diversos organismos internacionales, y la institucionalización del cambio de régimen bajo el paraguas de la responsabilidad de proteger.

\section{Discursos de libertad e intervenciones internacionales}

Como se ha afirmado, el liberalismo es consumidor de libertad y, por tanto, precisa producirla. Realiza esto último a través de una intervención que regula mediante la ley las condiciones de libertad en las que se desarrolla la vida del objeto/sujeto de gobierno.

Los discursos de libertad acompañan las intervenciones internacionales de dos maneras: como dato previo no respetado y como producto de la intervención. Así, por un lado, las intervenciones internacionales se montan sobre la idea de que a las poblaciones-objeto se les ha impedido desarrollar sus libertades naturales y, por otro lado, el objetivo de la intervención aparece vinculado con la creación de las condiciones para que éstas puedan desplegarse. Este último objetivo busca hacerse efectivo a través de la instauración de un marco jurídico-institucional democrático.

El sujeto democrático fue definido como un sujeto que se considera individuo libre y, por tanto, deseoso de y dispuesto a autogobernarse, a tomar "su futuro en sus propias manos". ${ }^{54}$ Así, la idea de sujeto democrático se encuentra íntimamente ligada a la concepción antropológica liberal de que el ser humano es natural y moralmente un individuo libre. Desde la lógica liberal, es su deseo esencial de libertad el que lo empuja a desear la democracia entendida como autogobierno y el que brinda a la forma democrática una legitimidad ética que se le niega a otras. A modo de ejemplo, el relato que primó sobre los levantamientos árabes de 2010-

54 Naciones Unidas, Secretario General, "Secretary-General's Remarks to the Security Council on Libya”, 26 de febrero de 2011. 
2011 los caracterizaba como revoluciones democráticas animadas por el "deseo de libertad" que "habita en cada ser humano". ${ }^{55}$ De allí que fueran consideradas expresiones de "aspiraciones legítimas de libertad". 56

Por otra parte, al plantear que el deseo de libertad es natural y que puede efectivizarse en un marco democrático, estos discursos igualan a todos los seres humanos, universalizando también la idea de democracia. Así, en el marco de prácticas intervencionistas liberales, se somete a sus espectadores a una constante repetición de estos discursos de libertad, generando empatía con otros distantes. De este modo, se refuerza la idea de la libertad como principio natural de la humanidad y se otorga a la democracia un carácter mesiánico, restaurador de un orden natural mancillado.

Ahora bien, este discurso no funciona únicamente dentro de las sociedades "liberales avanzadas", sino globalmente. Esto queda en evidencia en las demandas de las distintas poblaciones que se rebelan contra gobiernos que son caracterizados como no-democráticos. En efecto, es este último carácter el que otorga a estas poblaciones legitimidad global para sus demandas y el que habilita que la "comunidad internacional” acompañe estos levantamientos. De este modo, esta subjetivación genera presión internacional, no sólo de organizaciones de la sociedad civil global, de instituciones internacionales y de Estados específicos, sino también de sectores de la propia población blanco que aparecen demandando la intervención democratizadora, deviniendo no sólo objeto, sino también sujeto de gobierno. Fue el caso de la oposición libia en Benghazi, que elevó una petición de instauración de una zona de exclusión aérea, previo a la intervención en el país norafricano. Así, este elemento cumple

55 "Opening remarks by NATO Secretary General Anders Fogh Rasmussen at the meeting of NATO Defence Ministers, Brussels", 10 de marzo de 2011, www.nato.int

56 Naciones Unidas, Secretario General, "Remarks to the Global Creative Forum Dinner (as prepared for delivery)", Ban Ki-moon, 22 de febrero de 2011, www.un.org 
una función de subjetivación, aun cuando la democratización no se sustancie en la efectiva transformación del Estado. Por esta razón, es posible hablar de sujeto democrático a nivel global, incluso si no todos los Estados del globo son efectivamente democracias.

Los discursos de libertad encuentran un lugar en el dispositivo democrático global al homologar libertad y democracia. Ejemplos de esta homologación son fácilmente hallables en discursos de diversas administraciones de Estados Unidos. Así, en el contexto de la invasión a Iraq, el presidente Bush afirmaba: "El éxito de la democracia iraquí enviará las noticias desde Damasco a Teherán, de que la libertad puede ser el futuro de cada nación". ${ }^{57}$ Por su parte, en el marco de la intervención en Libia en 2011, la administración Obama sentenciaba: "La libertad está en el aire. Y la democracia está emergiendo en países que por generaciones no conocieron otra cosa que el gobierno autoritario". ${ }^{58}$ De este modo, se equipara vivir en libertad y vivir en democracia. En tanto y en cuanto la libertad se considera un valor abstracto, la homologación de ambos términos conduce a ubicar la democracia en el campo de la ética, convirtiéndola en un imperativo moral. Así, esta homologación se sustantiva en la legitimación del intervencionismo en las condiciones de libertad, bajo la forma del establecimiento de un marco jurídico-institucional (la democracia liberal), incidiendo en la producción de los sujetos necesarios para el ejercicio del gobierno liberal global.

\section{Elemento epistémico}

Este segundo elemento constitutivo del dispositivo democrático global refiere los modos en los que la democracia ha

57 "Radial Message from the President", White House, 5 de enero de 2004.

58 "Remarks by Vice President Joe Biden in Chisinau, Moldova", White House, 3 de noviembre de 2001. 
pasado, paulatinamente, a formar parte de la disciplina de las RI. Es un elemento que supone la existencia de agentes con autoridad para la producción de conocimiento que se considera verdadero.

La democracia ingresó al campo disciplinar de las RI de la mano de las teorías liberales que plantearon que el tipo de régimen doméstico es una variable a tener en cuenta al momento de pensar la política exterior de los Estados. En este marco emergió la tesis de la paz democrática (TPD), que postula que los Estados democráticos no hacen la guerra entre sí, y tiene como referentes fundamentales a tres autores: Kant, Doyle y Russett. Si el primero fue el encargado de postular en el siglo XVIII la posibilidad de una paz perpetua, basada en la forma de gobierno republicana, ${ }^{59}$ los otros dos actualizaron su teoría ${ }^{60}$ y plantearon costos y beneficios de su aplicación. ${ }^{61}$ De este modo, la TPD vincula a la democracia con la paz, añadiéndole un nuevo valor ético.

Por otra parte, desde esta perspectiva, la afirmación de que los Estados democráticos actúan de modo distinto hacia los Estados de su mismo tipo que hacia aquellos que no lo son, refuerza la idea de que la democracia es el único régimen político legítimo. En efecto, esta afirmación se basa en el supuesto de que los únicos Estados que tienen derecho a no sufrir intervenciones extranjeras son los Estados democráticos, porque son legitimados por el consenso de sus ciudadanos.

El momento de mayor dinamismo de la TPD tuvo lugar durante el proceso de la finalización de la Guerra Fría, cuando el liberalismo como enfoque teórico de RI, como doctrina económica y política, y como racionalidad de gobierno

${ }^{59}$ I. Kant, La paz perpetua, Buenos Aires, Bureau Editor, 2000.

60 M. Doyle, "Kant, Liberal Legacies and Foreign Affairs", Parte 1, Philosophy and Public Affairs, vol. 12, núm. 3, 1983, pp. 205-235; y M. Doyle, "Kant, Liberal Legacies and Foreign Affairs", Parte 2, Philosophy and Public Affairs, vol. 12, núm. 3, 1983, pp. 323-353.

${ }^{61}$ B. Russett, Grasping the Democratic Peace. Principles for a Post-Cold War World, New Jersey, Princeton University Press, 1993. 
global, comenzó a imponerse paulatinamente, ${ }^{62}$ En este marco, otro referente de las RI, Francis Fukuyama, afirmó que se había llegado al "punto final de la evolución ideológica de la humanidad y la universalización de la democracia liberal occidental como la forma final del gobierno humano". ${ }^{63}$ El efecto performativo de esta proposición epistémica fue puesto en evidencia por Slavoj Žižek cuando afirmó que todos -incluso los pensadores de izquierda- "hemos devenido fukuyamistas". ${ }^{64}$ Con esas pocas palabras, Žižek daba cuenta de los efectos de este discurso sobre la subjetividad, dejando en claro el deseo global de vivir en democracia.

Más allá de sostenerse sobre la equiparación entre libertad y democracia y sus vínculos con la paz, el aludido deseo también es producto de la relación íntima que se establece entre democracia y derechos humanos, puesto que se supone que la primera no habilita la violación de los últimos. Este supuesto sostenido por estas voces de autoridad ha tenido tal impacto en la subjetividad global que ha permitido el cambio en el significado de soberanía ${ }^{65}$ y la consiguiente pérdida de importancia relativa del principio de no-intervención. De esta manera, ha impactado en la producción normativa de la responsabilidad de proteger que, a su vez y como se verá, ha servido para legitimar prácticas políticas intervencionistas a nivel internacional, tendientes a la democratización/liberalización de Estados no-liberales (cambio de régimen).

62 B. Jahn, Liberal Internationalism. Theory, History, Practice, Londres, Palgrave Macmillan, 2013.

${ }^{63}$ F. Fukuyama, “¿El fin de la historia?”, Centro de Estudios Públicos, 1989, pp. 6-7.

${ }^{64}$ S. Žižek, "Philosopher Slavoj Žižek on Democracy Now- 2/6" (archivo de video), 11 de marzo de 2008, YouTube, en www.youtube.com

65 Véase K. Annan, "Two concepts of sovereignty", The Economist, 18 de septiembre de 1999 . 


\section{Prácticas de democratización}

Estos desarrollos no quedaron relegados al campo epistémico, sino que calaron en las distintas esferas de decisión política. En este sentido, como se planteó anteriormente, el dispositivo democrático global no ejerce sus efectos de subjetividad únicamente sobre la población objeto de las intervenciones, sino que también constituye a sus espectadores y a los responsables de adoptar decisiones, uno de los elementos que explica que ésta haya pasado a ocupar un lugar privilegiado en la agenda de política exterior de Estados Unidos y de los organismos internacionales.

El tercer elemento que, formando red con los otros, constituye el dispositivo democrático global es la práctica política de democratización de espacios no-liberales. Es válido aclarar que en este apartado el texto no abarca la totalidad de la política de democratización en el plano global, sino que busca brindar algunos ejemplos para graficar la afirmación de que existen prácticas políticas de imposición de la democracia liberal, más allá de que éstas sean exitosas o no, es decir, más allá de que la democracia se despliegue efectivamente en los Estados intervenidos.

De acuerdo con Sadiki, Estados Unidos ha colocado más fondos en la difusión de la democracia liberal que ningún otro Estado u organización no gubernamental. ${ }^{66}$ Esta política de democratización aparece vinculada con la TPD desde la administración de George H. W. Bush, manteniéndose presente a lo largo de las distintas administraciones tanto demócratas como republicanas. ${ }^{67}$

${ }^{66}$ L. Sadiki, Rethinking Arab Democratization: Elections without Democracy, Nueva York, Oxford University Press, 2009, p. 161.

${ }^{67} \mathrm{El}$ contraargumento que postula el apoyo por parte de la potencia norteamericana a gran cantidad de gobiernos autoritarios o golpes contra la democracia en países periféricos es válido. Lo sostenido hasta aquí no lo desconoce ni lo contradice: por un lado, señala una política de corte estratégico, tendencial, que no implica que, por cuestiones tácticas, 
El objetivo de estas políticas ha sido la intervención en Estados no-liberales a fin de modificar sus estructuras constitucionales con base en leyes macro que favorezcan ciertas libertades de las poblaciones (de mercado, de reunión, de expresión, de competencia, de religión, etc.). Es posible brindar como ejemplo de esto el caso de la intervención en Iraq en 2003. En esa oportunidad, la Autoridad Provisional de la Coalición ${ }^{68}$ emitió cien órdenes que apuntaban a modificar las condiciones de libertad de los iraquíes. De entre éstas, la que más atención ha acaparado ha sido la número 39, tendiente a liberalizar la economía de Iraq. No obstante, para los fines de este trabajo, otras son igualmente destacables. En efecto, las órdenes aspiran a producir y administrar la libertad de los gobernados. Así, por ejemplo, la orden 19 tiene como finalidad crear y regular la libertad de reunión "para promover la libertad del pueblo iraquí a manifestarse de un modo pacífico y ordenado". ${ }^{69}$ Asimismo, la número 65 se propone la regulación de la radiodifusión con el objetivo de brindar las condiciones que permitan "el completo ejercicio de la libertad de expresión".70

El despliegue de estas libertades se cree posible en un marco democrático. Así, la orden recientemente citada afirma que "el debate abierto y riguroso basado en el libre intercambio de la información es esencial para el desarrollo de una democracia moderna". ${ }^{71}$ Asimismo, la Ley de Administración de la Transición-base para la posterior redacción de la

se siga sosteniendo a gobiernos no-democráticos; por otro lado, considera que los golpes tienen lugar contra democracias no-liberales.

${ }^{68}$ Esta institución supuso el establecimiento de un gobierno colonial en Iraq y fue legitimada por el Consejo de Seguridad de las Naciones Unidas a través de la resolución 1483 de 2003. Entre mayo de 2003 y junio de 2004, la APC se encargaría de fijar pautas económicas, políticas y culturales que tenían como objetivo la liberalización de Iraq.

${ }^{69}$ Coalition Provisional Authority, Order 19, "Freedom of Assembly", en: https:/ / govinfo.library.unt.edu

70 Coalition Provisional Authority, Order 65, "Iraqi Communications and Media Commission”, en: https://govinfo.library.unt.edu

${ }^{71}$ Loc. cit. 
constitución iraquí, que planteaba el objetivo de hacer de Iraq una democracia, en su artículo 13 señalaba la necesidad de una serie de libertades para que ésta pudiera desarrollarse: libertades públicas y privadas, libertad de expresión, de reunión y manifestación pacíficas, libertad para unirse y formar partidos políticos, libertad de movimiento, de pensamiento, de religión, elecciones libres y competitivas, entre otras. ${ }^{72}$

De este modo, más allá de su éxito o de su fracaso, han existido políticas de democratización de distintos países del Sur global a través de una intervención que se ha enfocado en transformar el marco regulatorio en el que se desarrolla la vida de la población, creando libertades que permitan la emergencia de un Estado gubernamentalizado.

Estas prácticas también son detectables en instituciones internacionales. A modo de ejemplo, en el seno de la Organización de las Naciones Unidas (ONU), la democracia ha tomado un lugar cada vez más prominente. Así, se ha hecho eco de la vinculación entre paz y democracia al sostener que "la libertad, la paz, la seguridad, la estabilidad doméstica, el respeto por los derechos humanos, el Estado de derecho, la igualdad de género y las políticas orientadas al mercado y un compromiso por sociedades justas y democráticas [...] se refuerzan mutuamente". ${ }^{73}$ También a través de distintos documentos, la onU ha reforzado la vinculación entre derechos humanos y democracia, postulando que la promoción de la democracia disminuye las posibilidades de la guerra y el riesgo de violación de los derechos humanos: ${ }^{74}$ "Creo que en

72 Coalition Provisional Authority, "Law of administration for the state of Iraq for the transitional period", 8 de marzo de 2004, en: http:// www.au.af.mil/

73 Naciones Unidas, Asamblea General, 2005 World Summit Outcome, 16 de septiembre de 2005, A/RES/60/1.

74 Naciones Unidas, Asamblea General, In Larger Freedom: Towards Development, Security and Human Rights for All, Reporte del Secretario General, 26 de mayo de 2005, A/59/2005/Add.3; Naciones Unidas, Secretario General, "Secretary-General's Message on International Day of Democracy", 15 de septiembre de 2009. 
2005 deberían tomarse decisiones para [...] apoyar esfuerzos para instituir y profundizar la democracia en las naciones alrededor del globo". ${ }^{75}$

Estas prácticas, acompañadas de discursos con sus audiencias globales, refuerzan la vinculación entre paz, derechos humanos, libertad y democracia, ayudando a hacer de esta última un principio ético y, junto con los anteriores elementos, funcionan como "caja de resonancia" para la constitución de un sujeto global deseante de vivir en democracia.

\section{$L$ a responsabilidad de proteger $(R d P)$}

La inclusión de la norma RdP en la noción de dispositivo democrático global se explica tanto teórica como prácticamente. Su importancia radica tanto en que habilita el intervencionismo internacional como en que alienta la democratización. En efecto, la norma postula tres responsabilidades: 1) la responsabilidad de prevenir, atacando las causas del riesgo de las poblaciones de ser víctimas de violaciones de derechos humanos; 2) la responsabilidad de reaccionar ante estas últimas, respondiendo con "medidas apropiadas, que pueden incluir medidas coercitivas [...] y, en casos extremos, la intervención militar", ${ }^{76}$ y 3) la responsabilidad de reconstruir, actuando sobre las causas que generaron la desprotección de la población.

Los análisis de la RdP han tendido a centrarse en la segunda responsabilidad. Para los fines de este artículo, interesa enfocarse en la primera y en la última de éstas pues, debido a las relaciones establecidas entre democracia y derechos humanos, es allí donde pueden encontrarse los lazos más estrechos entre la primera y la RdP. La vinculación en-

75 Naciones Unidas, Asamblea General, In Larger Freedom..., op. cit., pp. 35-36.

76 International Commission on Intervention and State Sovereignty, ICISs, The Responsibility to Protect, Ottawa, International Development Center, 2001, p. 29. 
tre prevención, democracia y RdP quedó en evidencia en el informe del secretario general de las Naciones Unidas de 2012, titulado RdP: Respuesta a tiempo y decisiva. Allí puede leerse que "la forma más efectiva de prevención" de los crímenes a los que responde la RdP "radica en la administración constructiva de la diversidad para promover una buena gobernanza, igualdad, inclusión, respeto por los derechos humanos y por las libertades fundamentales y la observancia de valores y prácticas democráticas". 77

La otra responsabilidad que se encuentra directamente relacionada con la de prevenir es la de reconstruir, a la cual sigue lógica y prácticamente a la responsabilidad de reaccionar. Según asevera la norma bajo análisis, la reconstrucción debe hacerse con la vista puesta en las causas que generaron en primer lugar la intervención y con el fin de lograr la prevención de futuras violaciones masivas de derechos humanos. De acuerdo al documento de la RdP, estas causas radican en problemas estructurales identificados en el informe de 2001 del Secretario General de las Naciones Unidas titulado Prevención de los conflictos armados. Este último informe -"respaldado completamente"78 por la norma bajo análisis- identifica dos tipos de causas de conflicto: las socioeconómicas y las políticas. Respecto de estas últimas, "la promoción de los derechos humanos, la buena gobernanza, el Estado de derecho y la democratización" son consideradas como "las áreas más importantes para la acción preventiva". ${ }^{79}$

Asimismo, dicho documento diferencia las causas "de raíz” de las causas directas de un conflicto. Entre las primeras, consideradas de importancia fundamental por la RdP, se reconocen algunas de índole político, vinculadas con "nece-

77 Naciones Unidas, Secretario General, “Secretary-General's remarks to General Assembly Informal Interactive Dialogue on Responsibility to Protect: Timely and Decisive Response”, 5 de septiembre de 2012.

${ }^{78}$ International Commission on Intervention and State Sovereignty, op. cit. p. 19.

79 Naciones Unidas, Secretario General, Prevention of Armed Conflict. Report of the Secretary-General, 7 de junio de 2001, A/55/985-S/2001/574. 
sidades y deficiencias [...] en la institucionalidad democrática y en la construcción de capacidades; en la distribución del poder constitucional, en la alternancia de poder y arreglos de redistribución; [...] en el apoyo a la libertad de prensa y al gobierno de la ley; en la promoción de la sociedad civil..." ${ }^{80}$

De esta manera, si bien no explicita la necesidad de la democratización como base de la reconstrucción tras la intervención, las relaciones entre prevención, democracia y RdP dan una primera pista del lugar de la democracia liberal en la responsabilidad de reconstrucción.

Puede entregarse una segunda pista por la puesta en práctica de la RdP en el caso de la intervención en Libia en 2011. Ésta tuvo lugar en el marco de los levantamientos árabes que fueron leídos y escritos a través del lenguaje de la democracia. A partir del análisis de estos acontecimientos, Beham y Janik afirman que la "RdP ha transformado el discurso sobre Libia y Siria, disfrazando una agenda democrática con expresiones humanitarias", 81 y concluyen que aquello a lo que se hace referencia como RdP "se desempeña en la práctica como lo que podría denominarse una 'responsabilidad de democratizar' ". 82

Cabe recordar que la intervención en Libia liderada por la OTAN en 2011 estuvo basada en la Resolución 1973 del Consejo de Seguridad de Naciones Unidas, que fundamentó la instauración de una zona de exclusión aérea sobre territorio libio con el concepto de RdP. Ahora bien, la acción de las potencias liberales no se restringió al mandato de protección, sino que plantearon que para lograr ese objetivo era preciso un cambio de régimen. En efecto, si se determina

${ }^{80}$ International Commission on Intervention and State Sovereignty, op. cit, p. 24.

${ }^{81}$ M. Beham y R. Janik, "A 'Responsibility to Democratise'? The 'Responsibility to Protect' in Light of Regime Change and the 'Pro-Democratic' Intervention Discourse", R. Barnes y V. Tzevelekos, Beyond Responsibility to Protect: Generating Change in International Law, Cambridge, Intersentia, 2016, p. 53.

${ }^{82}$ Loc. cit. 
que las "causas del riesgo de las poblaciones" están vinculadas a la falta de democracia, la reconstrucción supone la implantación de un régimen democrático allí donde éste no existía.

\section{ObSERVACIONES FINALES}

Los discursos de libertad, la construcción de conocimiento, las prácticas políticas y las elaboraciones normativas tienen un importante efecto en las concepciones sobre nosotros mismos. El texto buscó articular estos diversos elementos en la conformación de un dispositivo democrático global cuyo efecto radica en la constitución de un sujeto democrático, es decir, un sujeto que se considera naturalmente libre y que, por lo tanto, desea ejercer dicha libertad a través del autogobierno, el que -a su vez- adopta la forma de la democracia. Así, el artículo se propuso reflexionar en torno a las condiciones de posibilidad y a los efectos del funcionamiento de este dispositivo, postulando que el sujeto que produce funciona como predicado del gobierno liberal global.

Partiendo de la analítica de la gubernamentalidad, éste se definió como un gobierno basado en la libertad de los gobernados. Esta afirmación se pretende crítica y, en ningún caso, aspiracional. La aclaración es necesaria puesto que esta mirada suele ser criticada por académicos que consideran los valores liberales como valores universales, ahistóricos y, por lo tanto, positivos. ${ }^{83}$ Así, la idea de que la democracia es un dispositivo del gobierno liberal global provoca una incomodidad inmediata, sobre todo en aquellos que, constituidos por este discurso, consideran a la democracia como un valor imposible de ser criticado. Estos académicos críticos tienden a sostener que las políticas de democratización a las

${ }^{83}$ Esto queda claro por ejemplo en J. Selby, "Engaging Foucault: Discourse, Liberal Governance and the Limits of Foucauldian IR", International Relations, vol. 21, núm. 3, 2007, pp. 324-345. 
que se hizo referencia anteriormente forman parte de una retórica hipócrita en la que la democracia se utiliza como instrumento de legitimación, ocultando intereses materiales inconfesables. La perspectiva metodológica de este artículo, en cambio, parte de tomarse en serio los discursos de libertad, las prácticas políticas de democratización, las construcciones académicas que vinculan democracia con paz y con derechos humanos y las preocupaciones de las instituciones internacionales por crear una normativa que coloque al individuo por encima del Estado. Tomarse en serio estas prácticas discursivas y no-discursivas permite pensar en los efectos en la subjetividad que éstas tienen sobre nosotros.

La importancia de pensar la producción del sujeto democrático radica en que, tal como lo asevera Odysseos, la constitución de este modo de subjetividad supone el desplazamiento de otros, puesto que la construcción de un marco democrático consensuado en el plano global canaliza y administra los descontentos sociales a través de este lenguaje, desplazando otros modos de subjetividades y limitando las luchas a las de tipo democrático.

Este sujeto deseoso de ejercer su libertad a través del autogobierno aparece con claridad en los discursos que acompañan la emergencia de fenómenos como los de la llegada de Donald Trump a la presidencia de Estados Unidos, de la emergencia de "extremismos" en Europa o en la posibilidad de la llegada a la presidencia de Brasil de Jair Bolsonaro. La ansiedad que generan estos fenómenos se encuadra en un discurso que señala que la democracia está en riesgo, lo que conduce a la conclusión de que, por lo tanto, estaríamos ante la inminente desaparición del orden liberal mundial. Más allá de que este diagnóstico se sostiene sobre una definición muy restringida del liberalismo (que impide, por ejemplo, pensar en Trump, el extremismo y en Bolsonaro como efectos del mismo), la preocupación expresada globalmente por la salud de la democracia liberal es un indicador de la legitimidad de la que ésta goza y del fukuyamismo que nos gobierna. 
Según Deleuze y Guattari, cartografiar implica recorrer tierras inexploradas, dibujar mapas y diagramas que establecen relaciones. De este modo, la cartografía no reproduce relaciones supuestamente preexistentes, sino que es productiva. A su vez, esta característica le permite construir mapas modificables, posibles de multiplicarse. ${ }^{84}$ De allí que se haya explicitado que el objetivo del texto entregado no es hacer una ontología, cerrar una época bajo el signo de la democracia, sino cartografiar la posible existencia de una estrategia democrática global. ¿Es posible dar cuenta de un dispositivo democrático que actúa en el plano global? La cartografía entendida en este sentido no está vinculada con territorios geográficos, sino con dispositivos. Así, está relacionada con la producción de deseos, de subjetividades.

El concepto de dispositivo fue definido como una red de relaciones que se presentó en su uso metodológico, como una herramienta para establecer relaciones entre elementos de distinta naturaleza que en su confluencia resuenan produciendo subjetividades. Es posible pensar la noción de subjetividad aplicada a las relaciones internacionales sólo si estas últimas son entendidas como relaciones sociales. En este marco, la dimensión de la subjetividad desplaza al concepto de interés del centro del análisis de la política internacional y añade el de deseo. En efecto, las relaciones internacionales como relaciones sociales también están movidas por el deseo, que es constitutivo de los sujetos que las forman.

El dispositivo democrático global se definió como un dispositivo deslocalizado, condición de posibilidad y efecto del gobierno liberal global. Tal como se afirmó, ya que éste es consumidor de libertad, para efectivizarse precisa producirla. El sujeto necesario para el desarrollo de un gobierno consumidor de libertad es un individuo que se considere naturalmente libre y que, por lo tanto, tenga deseos de autogobernarse. La construcción de la noción de dispositivo

${ }^{84}$ G. Deleuze y F. Guattari, Mil mesetas. Capitalismo y esquizofrenia, Valencia, Pre-textos, 2004. 
democrático global buscó pensar cómo se construye este sujeto, articulando imperativos éticos, construcciones teóricas, prácticas políticas y normativas. Existen innumerables ejemplos y seguramente más elementos pueden añadirse a este primer mapa del dispositivo democrático global. Lo que se intentó a través de estas palabras es pensar la democratización del mundo y la construcción de los seres que lo habitan como sujetos democráticos como una de las estrategias de un modo de ejercicio del poder, sostenido sobre prácticas de libertad.

\section{BibLIOGRAFÍA}

Agamben, Giorgio, “¿Qué es un dispositivo?”, Sociológica, vol. 26, núm. 73, 2011, pp. 249-264.

Annan, Kofi, "Two concepts of sovereignty", The Economist, 18 de septiembre de 1999.

BArry, Andrew, Thomas Osborne y Nikolas Rose, "Introduction", A. Barry, T. Osborne y N. Rose (eds.), Foucault, and Political Reason. Liberalism, Neo-liberalism, and Rationalities of Government, Chicago, The University of Chicago Press, 1996.

Beham, Markus, y Ralph Janik, “A 'Responsibility to Democratise'? The 'Responsibility to Protect' in Light of Regime Change and the 'Pro-Democratic' Intervention Discourse", R. Barnes y V. Tzevelekos, Beyond Responsibility to Protect: Generating Change in International Law, Cambridge, Intersentia, 2016, pp. 53-70.

Burchell, Graham, "Peculiar interests: Civil society and 'governing the system of natural liberty' ", G. Burchell, C. Gordon, P. Miller, P. (eds.), The Foucault Effect. Studies in Governmentality, Chicago, The University of Chicago Press, 1991, pp. 119-150.

Cadahia, Luciana, "Entre la liturgia y el desencanto: la profanación del dispositivo democrático", A. Bermejo Salar, Umbrales filosóficos. Posicionamientos y perspectivas del pensamiento contemporáneo, Murcia, Ediciones de la Universidad de Murcia, 2010, pp. 61-82. 
Castro Gómez, Santiago, Historia de la gubernamentalidad. Razón de Estado, liberalismo y neoliberalismo en Michel Foucault, Bogotá, Siglo del Hombre Editores, 2010.

Cortez, David y Gabriel Orozco, "Gubernamentalidad, biopolítica y dispositivos en relaciones internacionales”, Eidos, núm. 26, 2017, pp. 210-237.

Dean, Mitchell, Governmentality. Power and Rule in Modern Society, Londres, Sage Publications, 2010.

, "Governmentality", B. Turner, C. Kyung-Sup, C. Epstein, P. Kivisto, W. Outhwaite, M. Ryan (eds.), The Wiley Blackwell Encyclopedia of Social Theory, Nueva Jersey, Wiley Blackwell, 2017.

Deleuze, Gilles y Félix Guattari, Mil mesetas. Capitalismo y esquizofrenia, Valencia, Pre-textos, 2004.

Dillon, Michael y Julian Reid, The liberal way of war. Killing to make life live, Nueva York, Routledge, 2009

Doyle, Michael, "Kant, Liberal Legacies and Foreign Affairs", Parte 1, Philosophy and Public Affairs, vol. 12, núm. 3, 1983, pp. 205235.

, "Kant, Liberal Legacies and Foreign Affairs", Parte 2, Philosophy and Public Affairs, vol. 12, núm. 3, 1983, pp. 323-353.

Foucault, Michel, Vigilar y castigar. El nacimiento de la prisión, Buenos Aires, Siglo xxi, 1985.

, "El sujeto y el poder", H. Dreyfus, P. Rabinow, Michel Foucault: Más allá del estructuralismo y la hermenéutica, México, UNAM, 1988.

, "Governmentality", G. Burchell, C. Gordon y P. Miller, The Foucault Effect. Studies in Governmentality, Chicago, University Press, 1991.

, "Le jeu de Michel Foucault", M. Foucault, Dits et écrits 3 (1976-1979), París, Gallimard, 1994, pp. 298-328.

—, Sécurité, territoire, population, París, Gallimard, 2004.

-, Nacimiento de la biopolítica, Buenos Aires, Fondo de Cultura Económica, 2007.

Funuyama, Francis, “¿El fin de la historia?”, Centro de Estudios Públicos, 1989, pp. 5-31. 
Gordon, Colin, "Governmental Rationality: An Introduction", G. Burchell, C. Gordon, y P. Miller, The Foucault Effect. Studies in Governmentality, Chicago, Chicago University Press, 1991.

Guattari, Félix y Rolnik, Suely, Micropolítica. Cartografía del deseo, Petrópolis, Traficantes de sueños, 2006.

Hindess, Barry, "Neoliberal Citizenship”, Citizenship Studies, vol. 6, núm. 2, 2002, pp. 127-143.

, "Liberalism -what's in a name?", W. Larner y W. Walters (eds.), Global Governmentality: Governing International Spaces, Nueva York, Routledge, 2004, pp. 23-39.

Jabri, Vivienne, "La guerre et l'État libérale démocratique”, Cultures et conflits, núm. 61, 2006, pp. 9-34

Jahn, Beate, Liberal Internationalism. Theory, History, Practice, Londres, Palgrave Macmillan, 2013.

Joseph, Jonathan, "Governmentality of What? Populations, States, and International Organisations, N. Kiersey y D. Stokes (eds.), Foucault and International Relations. New Critical Engagements, Nueva York, Routledge, 2011, pp. 51-65.

Kant, Immanuel, La paz perpetua, Buenos Aires, Bureau Editor, 2000.

Kiersey, Nicholas, "Neoliberal Political Economy and the Subjectivity of Crisis: Why Governmentality is not Hollow", N. Kiersey y D. Stokes (eds.), Foucault and International Relations. New Critical Engagements, Nueva York, Routledge, 2011, pp. 1-24.

LARNER, Wendy y Walters, William, "Introduction. Global Governmentality: governing international spaces", Larner, W. y Walters, W. (eds.), Global Governmentality: Governing International Spaces, Nueva York, Routledge, 2004, pp. 1-20.

Martínez Posada, Jorge E., "El dispositivo: Una grilla de análisis en la visibilización de las subjetividades", Tabula Rasa, núm. 19, 2013, pp. 79-99.

Opysseos, Louiza, “Liberalism's war, liberalism's order: Rethinking the global liberal order as a 'global civil war' ", documento preparado para Liberal Internationalism, workshop pre-ISA, San Francisco, 25 de marzo de 2008. 
, "Human Rights, Liberal Ontogenesis and Freedom: Producing a Subject for Neoliberalism?”, Millenium Journal of International Studies, vol. 38, núm. 3, 2010, pp. 747-772.

Ortiz Leroux, Sergio, "La interrogación de lo político: Claude Lefort y el dispositivo simbólico de la democracia”, Andamios, 2006, pp. 79-117.

Peeters, Hugues y Philippe Charlier, "Contributions a un théorie du dispositif”, Hermès, La Revue, vol.3, núm.25, 1999, pp. 15-23.

Raffnsoe, Sverre, Marius Gudmand-Hoyer, y Morten Thaning, "What is a Dispositive? Foucault's Historical Mapping of the Networks of Social Reality", s/publicar, 2014, en: https://www. academia.edu/

Rojas, Cristina, "Governing through the social: Representations of poverty and global governmentality”, W. Larner y W. Walters, (eds.), Global Governmentality: Governing International Spaces, Nueva York, Routledge, 2004, pp. 97-115.

Rose, Nikolas, O'Malley, Pat, Valverde, Mariana, “Governmentality”, Annual Review of Law and Social Sciences, núm. 2, 2006, pp. 83-104.

Russett, Bruce, Grasping the Democratic Peace. Principles for a PostCold War World, New Jersey, Princeton University Press, 1993.

Sadiki, Larbi, Rethinking Arab Democratization: Elections without Democracy, Nueva York, Oxford University Press, 2009.

Scotт, David, "Colonial Governmentality", Social Text, núm. 43, 1995, pp. 191-220.

Selby, Jan, "Engaging Foucault: Discourse, Liberal Governance and the Limits of Foucauldian IR", International Relations, vol. 21, núm. 3, 2007, pp. 324-345.

Sending, Olev J. y Iver B. Neumann, "Governance to Governmentality: Analyzing NGos, States and Power", International Studies Quarterly, núm. 50, 2006, pp. 651-672.

Thomas, Owen D., "Foucaultian Dispositifs as Methodology: The Case of Anonymous Exclusions by Unique Identification in India”, International Political Sociology, núm. 8, 2014, pp. 164-181.

VRASTI, Wanda, "Universal but not truly 'global': governmentality, economic liberalism, and the international", Review of International Studies, vol. 39, núm. 1, 2013, pp. 49-69. 
ZanotTi, Laura, "Governmentalizing the Post-Cold War International Regime: The un Debate on Democratization and Good Governance", Alternatives, núm. 30, 2005, pp. 461-487.

ŽıžEK, Slavoj, "Philosopher Slavoj Žižek on Democracy Now- 2/6" (archivo de video), 11 de marzo de 2008, YouTube, en www. youtube.com

\section{Documentos}

Coalition Provisional Authority, Order 19, "Freedom of Assembly", en: https://govinfo.library.unt.edu/

, Order 65, "Iraqi Communications and Media Commission", en: https://govinfo.library.unt.edu/

—, "Law of administration for the state of Iraq for the transitional period", 8 de marzo de 2004.

International Comission on Intervention and State Sovereignty, The Responsibility to Protect, Ottawa, International Development Center, 2001.

Naciones Unidas, Secretario General, In Larger Freedom: Towards Development, Security and Human Rights for All, Reporte del Secretario General, 26 de mayo de 2005, A/59/2005/Add.3.

, Secretary-General's Message on International Day of Democracy, 2009, 15 de septiembre de 2009.

7 de junio de 2001, A/55/985-S/2001/574.

, Secretario General, Remarks to the Global Creative Forum Dinner (as prepared for delivery)", Ban Ki-moon, 22 de febrero de 2011.

, Secretaría General, "Secretary-General's remarks to General Assembly Informal Interactive Dialogue on Responsibility to Protect: Timely and Decisive Response", 5 de septiembre de 2012.

, Secretario General, Secretary-General's Remarks to the Security Council on Libya, 26 de febrero de 2011.

, Responsibility to Protect: Timely and Decisive Response, 2012. 
, Responsibility to Protect: State Responsibility and Prevention, 2013.

-Naciones Unidas, Asamblea General, 2005 World Summit Outcome, 16 de septiembre de 2005, A/RES/60/1.

"Opening remarks by nATO Secretary General Anders Fogh Rasmussen at the meeting of NATO Defence Ministers, Brussels", Organización del Tratado del Atlántico del Norte, otAn, 10 de marzo de 2011.

"Radial Message from the President", White House, 5 de enero de 2004, en: www.whitehouse.gov

"Remarks by Vice President Joe Biden in Chisinau, Moldova", White House 3 de noviembre de 2011, en: www.whitehouse.gov 
